\title{
Effect of PCR Conditions on the Formation of Heteroduplex and Single-stranded DNA Products in the Amplification of Bacterial Ribosomal DNA Spacer Regions
}

\author{
Mark A. Jensen ${ }^{1}$ and Neil Straus ${ }^{2}$
}

${ }^{1}$ Central Research and Development Department, E.I. du Pont de Nemours \& Company (Inc.), Wilmington, Delaware 19880;

${ }^{2}$ Department of Botany, University of Toronto, Toronto, Ontario, Canada M5S 3B2

PCR amplifications of $165 / 235$ rDNA spacer regions were carried out from conserved 165 and 235 sequences for genomic DNA samples from strains representing 16 bacterial species (12 genera). Multiple products were produced containing conserved homologous sequences at the $3^{\prime}$ and $5^{\prime}$ ends, separated by highly variable internal spacer sequences. These products cross-hybridized forming heteroduplex DNA structures containing double-stranded ends surrounding an internal single-stranded loop. Singlestranded DNA was also produced in the amplification of rDNA spacer sequences. Fragments comprising the nonhomoduplex DNA components were identified by their susceptibility to removal by digestion with a singlestranded endonuclease. The relative formation of heteroduplex and single-stranded DNA was reduced by reaction conditions favoring primer/ template annealing, for example, higher ionic strength, higher primer concentration, and lower annealing temperature, as well as by decreasing the number of amplification cycles. Heteroduplex and single-stranded DNA structures were also generated by denaturing and reannealing spacer amplification products in the absence of polymerase activity. Whereas heteroduplex and single-stranded DNA structures provide additional information that is helpful in distinguishing between species of bacteria that produce similar homoduplex products, the mobility of heteroduplex and single-stranded DNA structures DNA structures is extremely sensitive to electrophoretic conditions.

$\mathbf{T}$ he past few years have seen rapid growth in the use of PCR as a method for amplifying specific genes from total genomic DNA to greatly shorten gene cloning procedures. Recently, PCR and other DNA amplification techniques have also been used as diagnostic tools to identify species and to create genetic markers for chromosome mapping. It has been shown that highly conserved repeated sequences found in bacterial genomic DNA can be used as generic priming sites for a broad range of species. Amplification reactions, where primer sequences derived from these conserved sequences are used, are capable of generating multiple PCR products with size distribution profiles that can be used in the differentiation of bacterial species. ${ }^{(1)}$ A second DNA amplification procedure, which has been used to produce genetic markers, makes use of amplification products that are generated through the use of single short primers (9-12 bases) of arbitrary sequence or longer primers at low stringency. ${ }^{(2,3)}$ The number and size distribution of these products, often referred to as randomly amplified polymorphic DNA (RAPD), or arbitrarily primed PCR (AP-PCR) fingerprints, has proven to be a useful tool for the differentiation of both prokaryotic and eukaryotic organisms. ${ }^{(2-5)}$

One feature common to each of these diagnostic DNA amplification procedures is that each of the products in a given reaction carries homologous $3^{\prime}$ and $5^{\prime}$ ends that flank a variety of heterologous internal sequences. If the flanking homologous sequences are sufficiently long, it is possible that DNA strands with heterologous centers could cross-hybridize. In later amplification cycles, when the products become relatively concentrated, the probability of such a recombination event is increased. Cross-hybridization products formed in the last amplification cycle would not be denatured and could form a significant portion of the final product profile.

In this paper, we describe how the amplification of prokaryotic ribosomal DNA (rDNA) spacer regions from conserved sequences in the flanking $16 \mathrm{~S}$ and $23 \mathrm{~S}$ genetic loci not only generates double-stranded intergenic spacers but also results in the appearance of both singlestranded structures and heteroduplex structures containing substantial singlestranded regions. The heteroduplex structures may produce perplexing PCR products in the absence of prior knowledge about the presence of repeated, divergent sequences in the genome being studied. Although the presence of these structures may add an additional diagnostic feature, their occurrence may be sufficiently dependent on minor changes in reaction conditions to require additional steps for the identification of the reaction products. Several methods are suggested to identify both heteroduplex and single-stranded structures and to control their appearance. 


\section{MATERIALS AND METHODS}

\section{DNA Amplification}

High-molecular-weight, bacterial genomic DNA was purified from cell lysates by two sequential chloroform/phenol extraction and ethanol precipitation steps. DNA was redissolved in a buffer containing $10 \mathrm{~mm}$ Tris and $1 \mathrm{~mm}$ EDTA, and its concentration was determined spectrophotometrically. DNA samples were diluted to a concentration of $50 \mathrm{ng}$ / $\mu l$ before amplification. The DNA amplification reactions were carried out using the Perkin-Elmer Cetus Ampliwax procedure. The standard set of amplification conditions consisted of a 3.0- $\mu$ l aliquot of a dNTP mixture (5 mM each) combined with $3.75-\mu$ l aliquots of two 17base oligonucleotide primers, G17 and L17, $(10 \mu \mathrm{M})$ and a $1.25-\mu \mathrm{l}$ aliquot of reaction buffer concentrate $(500 \mathrm{mM} \mathrm{KCl}$, $100 \mathrm{~mm}$ Tris- $\mathrm{HCl}$ at $\mathrm{pH} 8.3,15 \mathrm{~mm}$ $\mathrm{MgCl}_{2}$, and $0.003 \%$ gelatin) and $0.57 \mu \mathrm{l}$ of $100 \mathrm{~mm} \mathrm{MgSO}_{4}$. [In addition to the standard reaction conditions, $2 \times$ levels of both primers and variations in the G17/L17 concentration ratio were evaluated. The effect of a $2 \times$ level of reaction buffer was also examined. The addition of $0.57 \mu \mathrm{l}$ of $100 \mathrm{mM} \mathrm{MgSO}_{4}$ was omitted for the $2 \times$ reaction buffer conditions to maintain a constant $\mathrm{Mg}(\mathrm{II})$ concentration of $1.5 \mathrm{~mm}$ in all of the amplification reactions.] The reaction mixture was brought to a final volume of $32 \mu$ l with the addition of deionized water. An Ampliwax PCR Gem was added to each reaction tube, and the wax was melted by heating to $80^{\circ} \mathrm{C}$ for $10 \mathrm{~min}$. On cooling to room temperature, a solid wax layer was formed above the reaction mixture. On top of the wax layer a $0.75-\mu l$ aliquot of the bacterial genomic DNA was added. Native Taq DNA polymerase (PerkinElmer Cetus) was diluted $1 / 4$ in a solution of $1.0 \%$ Tween 20 and $10 \mathrm{~mm}$ Tris-HCl (pH 8.0). A 2.4- $\mu$ l aliquot of the diluted polymerase solution was combined with either 2.5 or $5 \mu$ l of additional reaction buffer and a sufficient volume of deionized water to produce a final volume of $42 \mu \mathrm{l}$. This mixture was then added to the genomic DNA on top of the wax layer. The reaction tubes were sealed and heated to $94^{\circ} \mathrm{C}$ for $2 \mathrm{~min}$. When the wax layer melted, the two aqueous mixtures combined to produce a total reaction volume of $75 \mu$ l. Twenty or 25 amplification cycles were then performed on a Perkin-Elmer Cetus GeneAmp PCR Sys- tem 9600 according to the following format: $15 \mathrm{sec}$ at $94^{\circ} \mathrm{C}, 4 \mathrm{~min}$ at $61^{\circ}$ or $55^{\circ} \mathrm{C}$, and $1 \mathrm{~min}$ at $72^{\circ} \mathrm{C}$. The final cycle was followed by an additional $7 \mathrm{~min}$ at $72^{\circ} \mathrm{C}$ to complete partial polymerizations.

\section{Mung Bean Nuclease Digest}

A 30- $\mu$ l aliquot of the amplification reaction was removed and added to $10 \mu \mathrm{l}$ of digest buffer ( $240 \mathrm{~mm}$ sodium acetate at $\mathrm{pH} 5.4,8 \mathrm{mM} \mathrm{ZnCl}_{2}$, and $20 \%$ glycerol). The mixture was combined with 8 units of mung bean nuclease and incubated for 5-10 min. The reaction was stopped by the addition of $4 \mu \mathrm{l}$ of $0.5 \mathrm{M}$ EDTA. Before electrophoresis, the digest product was passed through a G-50 spin column to remove excess salt.

\section{Electrophoresis and Imaging}

\section{Direct PCR Product}

A 2.5- $\mu \mathrm{l}$ aliquot of the PCR reaction mixture was combined with $1 \mu \mathrm{l}$ of loading buffer (15\% Ficoll, $5 \mathrm{~mm}$ EDTA, $0.1 \%$ SDS, and $0.1 \%$ xylene cyanol) and loaded onto a $4 \%$ acrylamide/bisacrylamide gel (29:1).

\section{Denatured PCR Product}

Denaturization was accomplished by combining $5 \mu$ l of amplification product with $10 \mu \mathrm{l}$ of deionized water and $6 \mu \mathrm{l}$ of loading buffer and then heating at $95^{\circ} \mathrm{C}$ for $3 \mathrm{~min}$. Samples were immediately placed in dry ice/ethanol and thawed on wet ice just before electrophoresis. A $10.5-\mu \mathrm{l}$ aliquot was loaded onto a $4 \%$ acrylamide/bisacrylamide gel (29:1).

All samples were electrophoresed in a $1 \times$ Tris-borate-EDTA running buffer for $55 \mathrm{~min}$ at a field strength of $14 \mathrm{~V} / \mathrm{cm}$. Following electrophoresis, the gels were stained for $15 \mathrm{~min}$ in a solution of ethidium bromide at $0.25 \mu \mathrm{g} / \mathrm{ml}$.

\section{Determination of PCR Product Sizes}

Molecular mass markers were constructed by amplifying regions of known length and sequence from the $r m B$ rRNA operon of Escherichia coli. ${ }^{(6)}$ The sizes of the fragments produced in the amplifications were calculated from the positions of these fragments relative to the molecular mass markers in the adjacent lane.
The uncertainty in the calculated sizes of the amplification products was $\sim 2 \%$.

\section{Identification of Bacterial Strains}

Bacterial strains were identified by observations of colonial morphology and Gram stains and by means of well-established biochemical tests. The species identification of all bacteria contained in the test panel was also confirmed by comparison of a ribotyping pattern with a pattern data base. ${ }^{(7,8)}$

\section{RESULTS}

\section{Primer Selection}

The amplification priming sites were selected from regions of highly conserved sequences found in the $16 \mathrm{~S}$ and $23 \mathrm{~S}$ regions adjacent to the intervening spacer region (see Fig. 1). Conserved sites were chosen to ensure that spacer amplification products would be generated for a broad range of bacteria without resorting to additional primer combinations. Priming sequences close to the 16S/23S intergenic spacer were chosen to ensure that variations in spacer size would result in maximum relative variations in PCR product sizes. The primer G17 was selected from a highly conserved region adjacent to the $16 \mathrm{~S} / 23 \mathrm{~S}$ spacer $\sim 50 \mathrm{nu}$ cleotides upstream from the spacer boundary (Fig. 1). ${ }^{(9)}$ The sequence for this oligonucleotide is GTGAAGTCGTAACAAGG. The primer L17 was selected from the five bacterial and four plant chloroplast $23 \mathrm{~S}$ sequences compiled by Gutell et al. (10) This sequence, CAAGGCATCCACCGTGT, is the most conserved $23 S$ sequence immediately following the spacer and is located $\sim 20$ bases downstream from the spacer boundary (Fig. 1). Primers for both the $16 \mathrm{~S}$ and $23 \mathrm{~S}$ regions were limited to a length of 17 bases because of species-dependent variations in sequence beyond these conserved regions. Although it would have been desirable to identify primers with a more similar GC content, such priming sites could not be found among the highly conserved sequences immediately flanking the $16 \mathrm{~S} / 23 \mathrm{~S}$ intergenic spacer.

\section{Amplification Product Profiles}

Amplifications of the spacer regions between the 16S and 23S rRNA genetic loci 


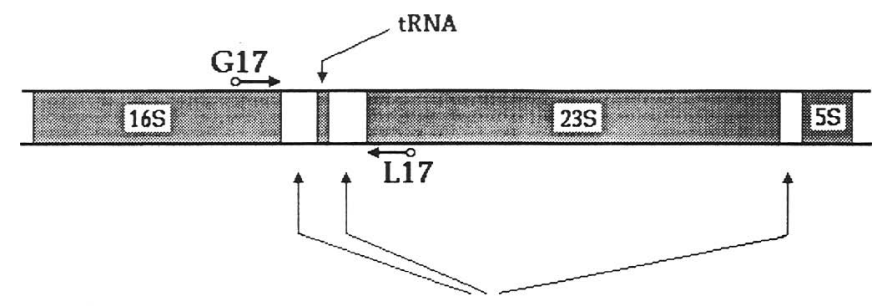

Hypervariable Spacer Regions

FIGURE 1 Schematic representation of an rRNA operon showing the approximate priming sites for the PCR amplification of the $16 \mathrm{~S} / 23 \mathrm{~S}$ spacer region. The number of tRNA genes in this spacer region is subject to variation. were run for 16 strains of bacteria representing 16 species and 12 genera. Representatives from the genera Listeria, Shigella, Staphylococcus, and Salmonella were chosen because the identification and characterization of these pathogenic microorganisms are of particular interest.

The initial amplification conditions that were investigated consisted of the following: reaction buffer, $25 \mathrm{mM} \mathrm{KCl}, 5$ $\mathrm{mM}$ Tris- $\mathrm{HCl}\left(\mathrm{pH} 8.3\right.$ at $\left.25^{\circ} \mathrm{C}\right), 1.5 \mathrm{~mm}$ $\mathrm{MgCl}_{2}$, and $0.00015 \%$ gelatin $(\mu \sim 0.03$ M); 0.2 mм each dNTP, $0.5 \mu \mathrm{M}$ each 17base primer. The following temperature profile was run for 25 cycles: $15 \mathrm{sec}$ at $94^{\circ} \mathrm{C}, 4 \mathrm{~min}$ at $61^{\circ} \mathrm{C}$, and $1 \mathrm{~min}$ at $72^{\circ} \mathrm{C}$. Amplifications run on bacterial genomic DNA under these conditions produced fragments that could be grouped loosely into three categories (see Fig. 2). The first group of products consisted of fragments in the size range of $280-850 \mathrm{bp}$. These products are consistent in size and number with those that were reported previously for the amplification of the 16S/ $23 S$ spacer region. ${ }^{(1)}$ A second intermediate group of fragments, which had not been observed previously, showed a mobility comparable with doublestranded DNA fragments in the 850- to 2300 -bp range. A third group of slowmoving fragments could be seen near the top of the gel in 14 of the 16 lanes. These fragments moved substantially slower than the 2.3-kb molecular mass marker. In comparisons with a HindIII digest of $\lambda$ DNA, most of these fragments traveled well behind the $23-\mathrm{kb}$ fragment (data not shown).

To demonstrate that $16 \mathrm{~S} / 23 \mathrm{~S}$ intergenic spacer regions are the source of the amplification products, E. coli, Shigella sonnei, Salmonella typhimurium and Salmonella enteritidis amplification reactions were digested by a series of restriction enzymes. The $E$. coli intergenic spacer, which contains a single tRNA ${ }_{2}^{\mathrm{Glu}}$ gene, should be cut by both BstBI and $X b a I$. StuI and PvuII should cut the tRNA ${ }_{1}^{\text {Ile }}$ and tRNA Ala genes, respectively, in the two-tRNA gene intergenic spacers of E. coli. ${ }^{(11,12)}$ Each of the E. coli, S. sonnei, $S$. typhimurium, and $S$. enteritidis amplification products in the 280 - to 850 -bp size range were found to contain a combination of either PvuII and StuI, or BstBI and $X b a I$ restriction sites (data not shown). The presence of these sites is a strong indication that the amplification products contain tRNA Ala tRNA $_{1}^{\text {Ile }}$, and tRNA ${ }_{2}^{\text {Glu }}$ genes and are generated from rDNA spacer regions.

Examples of the three fragment size groups can be seen in Figure 2, lane 1, where the products of the amplification of $E$. coli genomic DNA are shown. The fragments observed at 480 and 540 bp have been reported previously. ${ }^{(1)}$ Such is not the case for the fainter fragment observed at $520 \mathrm{bp}$. The two fragments apparently in the size range of 970-1200 bp and the additional fragments near the top of the gel have not been reported previously and are all inconsistent with our current understanding of the $16 \mathrm{~S} /$ $23 S$ spacer regions in $E$. coli. Amplification products apparently in the size range of 800-2300 bp were also observed for the remaining 15 species of bacteria in the test panel. Except for the Enterococcus faecalis strain in lane 4 and the Listeria welshimeri strain in lane 10, each species also showed additional fragments that moved substantially slower than the $2.3-\mathrm{kb}$ molecular mass marker.

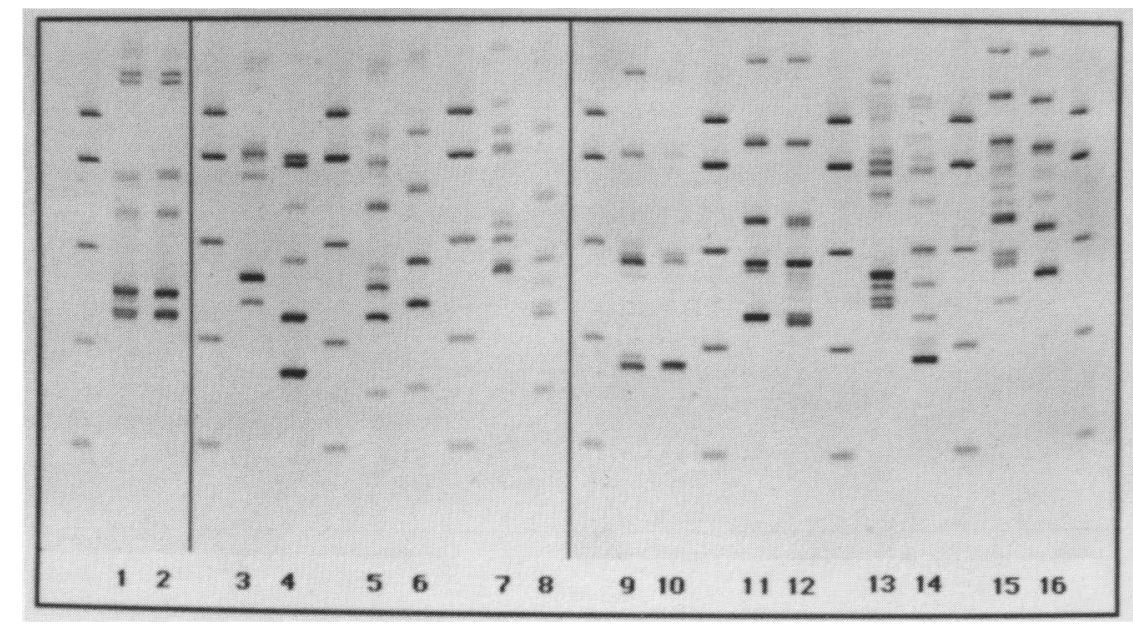

FIGURE 2 Composite photograph showing PCR amplification products for the following bacterial genomic DNA samples (species is followed by ID number): (Lane 1) Escherichia coli (6); (lane 2) Shigella sonnei (699); (lane 3) Serratia marcescens (10); (lane 4) Enterococcus faecalis (130); (lane 5) Enterobacter cloacae (123); (lane 6) Citrobacter freundii (744); (lane 7) Hafnia alvei (748); (lane 8 Klebsiella pneumoniae (210); (lane 9) Listeria monocytogenes (653); (lane 10) Listeria welshimeri (1174); (lane 11) Salmonella typhimurium (586); (lane 12 Salmonella enteritidis (737); (lane 13) Staphylococcus aureus (684); (lane 14) Staphylococcus epidermidus (382); (lane 15) Proteus mirabilis (257); (lane 16) Proteus morganella (363). Standard of amplification conditions consisted of 0.2 mM dNTPs, $0.5 \mu \mathrm{M}$ primers (G17 and L17), and a reaction buffer of $25 \mathrm{~mm} \mathrm{KCl}, 5 \mathrm{~mm}$ Tris- $\mathrm{HCl}$ ( $\mathrm{pH}$ 8.3), $1.5 \mathrm{mM} \mathrm{MgCl}_{2}$, and $0.00015 \%$ gelatin. A total of 25 cycles were run under the following conditions: $15 \mathrm{sec}$ at $94^{\circ} \mathrm{C}, 4 \mathrm{~min}$ at $61^{\circ} \mathrm{C}$, and $1 \mathrm{~min}$ at $72^{\circ} \mathrm{C}$. The final cycle was followed by an additional $7 \mathrm{~min}$ at $72^{\circ} \mathrm{C}$. Unlabeled lanes contain molecular mass markers of the following sizes: $228,412,693,1331$, and 2306 bp. PCR products were electrophoresed in $4 \%$ acrylamide/bisacrylamide (29:1) using a 1.0 $\times$ Tris-borate-EDTA running buffer for $55 \mathrm{~min}$ at a field strength of 14 $\mathrm{V} / \mathrm{cm}$. Following electrophoresis, the gels were stained for $15 \mathrm{~min}$ in a solution of ethidium bromide at $0.25 \mu \mathrm{g} / \mathrm{ml}$. 


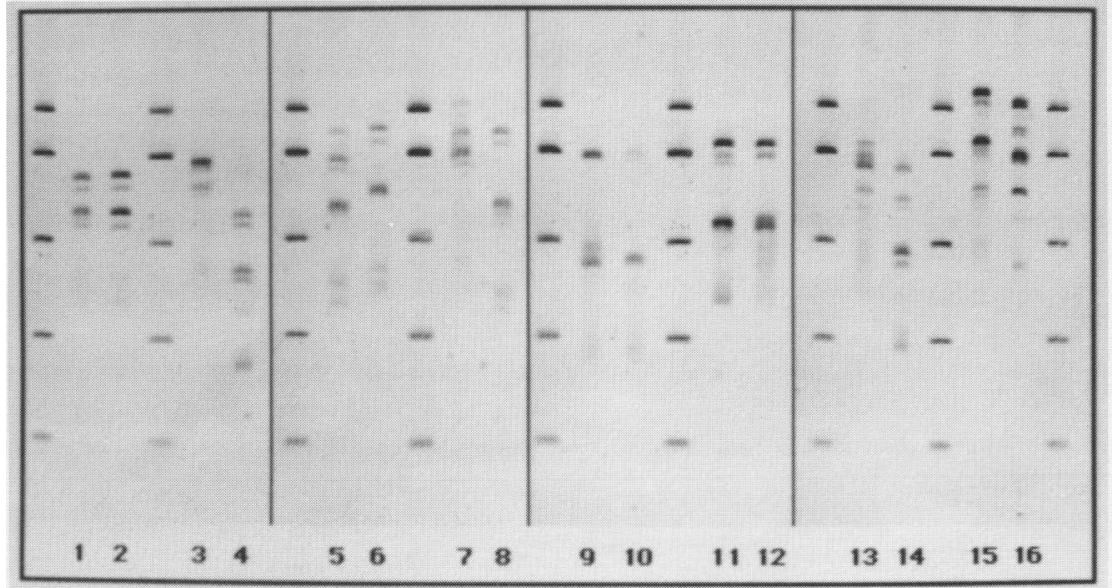

FICURE 3 Composite photograph showing the denatured amplification products from Fig. 2. Products were denatured by mixing $5 \mu \mathrm{l}$ of product with $10 \mu \mathrm{l}$ of deionized water and $6 \mu \mathrm{l}$ of loading buffer ( $15 \%$ Ficoll, $5 \mathrm{~mm}$ EDTA, $0.1 \%$ SDS, and $0.1 \%$ xylene cyanol) and heating at $95^{\circ} \mathrm{C}$ for $3 \mathrm{~min}$. Samples were immediately placed in dry ice/ethanol and later thawed on wet ice just before electrophoresis. Sample location and lane designation are the same as in Fig. 2. Unlabeled lanes contain molecular mass markers. Molecular mass markers, gel composition, electrophoresis, and staining conditions are described in Fig. 2.

The apparent size ranges of both the second and third fragment groups are substantially larger than any prokaryotic $16 S / 23 S$ spacer regions reported previously.

It seems unlikely that the two groups of slower moving products are doublestranded DNA resulting from priming events occurring outside the rDNA spacer region. The use of a $61^{\circ} \mathrm{C}$ annealing temperature with a reaction buffer ionic strength of $0.03 \mathrm{M}$ results in a very-highstringency amplification reaction for 17base primers. When the annealing temperature is increased to $>61^{\circ} \mathrm{C}$, there is a rapid falloff in the production of all amplification products. This suggests that amplifications resulting from partial primer sequence matches should be highly unfavored under these conditions. The likelihood that all 16 bacteria strains in the test panel contain sequences outside the rRNA operon, which show near perfect matches with the 17 base rDNA sequences, seems rather remote.

Other possible sources of the two slower moving groups of PCR products are (1) single-stranded spacer amplification sequences and (2) heterogeneous DNA duplexes formed by cross-hybridizations between similar but not identical spacer amplification products. The formation of single-stranded DNA structures could result from asymmetry in either amplification efficiency or con- sumption of the G17 and L17 primers. In later cycles, when the ratio of primer to product is substantially reduced, any type of primer asymmetry in conjunction with the capacity of ribosomal sequences to form stable intramolecular structures may facilitate the formation of single-stranded DNA. Because of their single-stranded character, such structures would be expected to move slower than the corresponding double-stranded amplification products.

\section{Single-stranded rDNA Spacer Amplification Products}

To determine which of the PCR products in Figure 2 are single-stranded DNA, these products were denatured and separated under the same electrophoresis conditions (see Materials and Methods). It was necessary to maintain uniform electrophoresis conditions to ensure that single-stranded DNAs with the same sequence composition would have the same conformation and electrophoretic mobility. The electrophoretic mobility of the denatured PCR products is shown in Figure 3.

The electrophoretic mobility of the denatured DNAs was roughly comparable with double-stranded molecular mass markers in the size range of $650-2300$ bp. Many of the bands observed in Figure 3 corresponded directly to bands in Figure 2. This strongly suggests that some products generated under the standard amplification conditions shown in Figure 2 are single-stranded DNA. Additional bands were observed in Figure 3 that were not seen in Figure 2. These bands are believed to be either singlestranded sequences, which were present only as double-stranded PCR products in Figure 2, or labile intramolecular conformations of single-stranded DNA, which relax to more stable conformations in the final $72^{\circ} \mathrm{C}$ incubation of the amplification process.

\section{Primer Asymmetry}

To determine whether asymmetry in primer utilization contributes to the formation of single-stranded products, the amplification of $E$. coli $\mathrm{rDNA}$ spacers was carried out at ratios of $\mathrm{G} 17 / \mathrm{L} 17$ ranging from 0.125 to 8 . The results of these amplifications are shown in Figure 4. At ratios of $\mathrm{G} 17 / \mathrm{L} 17$ ranging from 0.125 to 1.0, the formation of the single-stranded DNA was relatively constant. When the ratio was increased to 2.0 , a decrease in single-stranded DNA formation began to be apparent. At a $\mathrm{G} 17 / \mathrm{L} 17$ ratio of 8.0 , single-stranded DNA products were barely visible. In the example of $E$. coli spacer amplification, asymmetric primer utilization clearly plays an important role in the formation of single-stranded DNA structures. This probably results from a combination of the higher GC content of L17 and the stringent annealing conditions that would augment the effects of differences in the base composition of the primers.

\section{Heteroduplex rDNA Spacer Amplification Products}

Because none of the bands in Figure 3 corresponded to the slowest moving fragments in Figure 2, these fragments are clearly not single-stranded DNA. One possible source of the slowest moving fragments may be the formation of heteroduplex DNA structures. Heterologous duplex DNA formation during PCR amplification and the effect of such duplex formation on electrophoretic mobility has been reported previously. ${ }^{(13-15)}$ Becker-André and Hahlbrock $^{(13)}$ reported the formation of double-stranded DNA heterodimers in the later cycles of PCR amplification. Hsieh and Griffith ${ }^{(14)}$ demonstrated that base deletions in one strand of a DNA duplex 


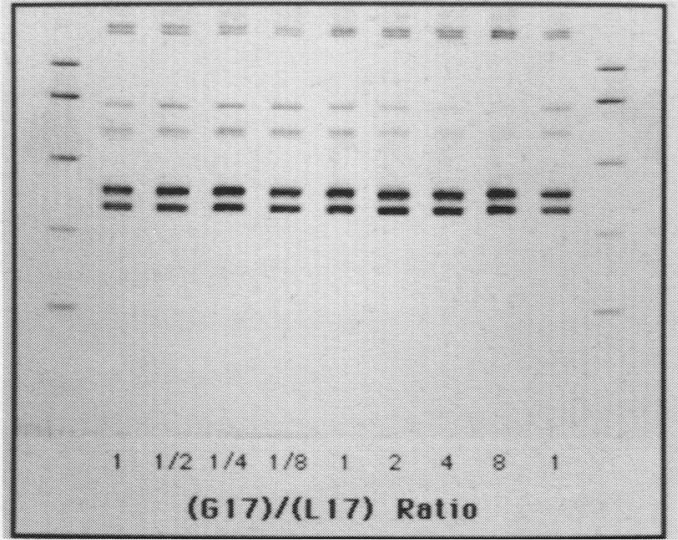

FICURE 4 Photograph showing the variation in PCR products for the amplification of the rDNA spacer of $E$. coli as a function of G17/L17 primer ratio. Amplification conditions are the same as described in Fig. 2 except for the primer concentrations. Individual lanes are labeled with the G17/L17 primer ratios. Ratios and the corresponding G17/L17 primer concentrations in the amplification reaction are as follows (in $\mu \mathrm{M}$ ): (1/8) $0.5 / 4.0,(1 / 4) 0.5 / 2.0,(1 / 2) 0.5 / 1.0,(1) 0.5 / 0.5$, (2) $1.0 / 0.5$, (4) $2.0 / 0.5$, and (8) 4.0/0.5. Unlabeled lanes contain molecular mass markers. Molecular mass markers, gel composition, electrophoresis, and staining conditions are described in Fig. 2.

resulted in significant decreases in electrophoretic mobility.

If dissimilar ribosomal spacer fragments are formed in the amplification reaction and if these fragments possess a high degree of homology in their terminal $3^{\prime}$ and $5^{\prime}$ sequences, then cross-hybridization of such fragments could compete with primer/template annealing in later amplification cycles when product concentration is highest. The resulting heteroduplex DNA would contain regions of both single- and doubledstranded DNA. The electrophoretic mobility of such heteroduplexes should be dependent on the portion of singlestranded sequence present in the structure. ${ }^{(14)}$ Heteroduplexes with a small number of sequence mismatches will contain only a small portion of singlestranded DNA and are expected to run slightly slower than their corresponding homoduplexes. Heteroduplexes, with composition $>50 \%$ single-stranded DNA, would be expected to move more slowly than the corresponding single-stranded structures that make up the heteroduplex. Because the electrophoretic mobility of the slowest moving group of products in Figure 2 is substantially less than any of the denatured amplification products (Fig. 3), it seems likely that the slowest moving group of products are heteroduplex DNA structures that contain a significant portion of single-stranded DNA.
The E. coli genome, which has been studied far more extensively than other members of the bacterial test panel, is known to contain seven $r r$ loci. Four of the $r m$ loci have spacer regions that contain a single tRNA Glu gene. In the remaining three $r m$ loci, each spacer region contains two-tRNA genes, tRNA 1 le and $\operatorname{tRNA}_{1 \mathrm{~B}}^{\mathrm{Ala}} \cdot{ }^{(6,11,12)}$ On the basis of known sequences for the flanking $16 \mathrm{~S}$ and $23 \mathrm{~S}$ regions and the intervening spacer regions, amplification products of the one-tRNA gene spacers and the twotRNA gene spacers should have 100 bases of homologous sequence at the $16 \mathrm{~S}$ side and 150 bases of homologous sequence at the $23 S$ side. $^{(6,11,12)}$ If the amplification products for these two gene types were to cross-hybridize, the resulting product would contain double-stranded sections of 100 and 150 bases at the $16 \mathrm{~S}$ and 235 ends, with an intervening single-stranded loop of 560 bases. A schematic of this type of cross-hybridization product is shown in Figure 5. This putative cross-hybridization product is an example of a heteroduplex structure with mobility that should be slower than its individual single-stranded components.

\section{Effect of Amplification Conditions on Product Composition}

The formation of single-stranded and heteroduplex DNA structures was found to be highly dependent on amplification reaction conditions. Figure 6 demonstrates the combined effects of the following modifications to the standard amplification conditions: (1) a $2 \times$ increase in reaction buffer at a constant 1.5 $\mathrm{mM} \mathrm{MgCl}_{2}$, (2) an increase in primer level from 0.5 to $1.0 \mu \mathrm{M}$, (3) a reduction in annealing temperature from $61^{\circ} \mathrm{C}$ to $55^{\circ} \mathrm{C}$, and (4) a reduction in cycle number from 25 to 20 . If any of these changes are introduced as single variations in the standard reaction conditions, a modest decrease in the formation of singlestranded and heteroduplex DNA is observed. When all of these modifications were combined, the result was a signifi-
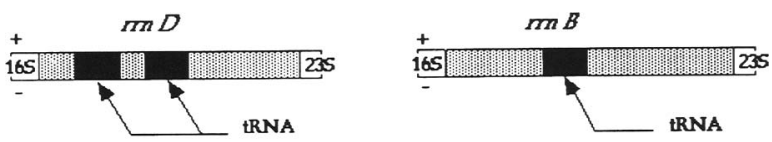

Homoduplex DNA spacer amplification products for $E$ coli
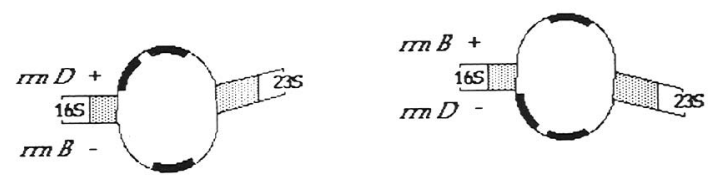

Heteroduplex DNA spacer amplification products for $E$. coli after product cross-hybridization

FIGURE 5 Schematic representation of the homologous duplex DNA structures formed in the amplification of two $16 \mathrm{~S} / 23 \mathrm{~S}$ ribosomal spacers of $E$. coli and of the proposed heterologous duplex DNA structures resulting from the cross-hybridization of these two amplification products. Stippled areas indicate spacer regions. 


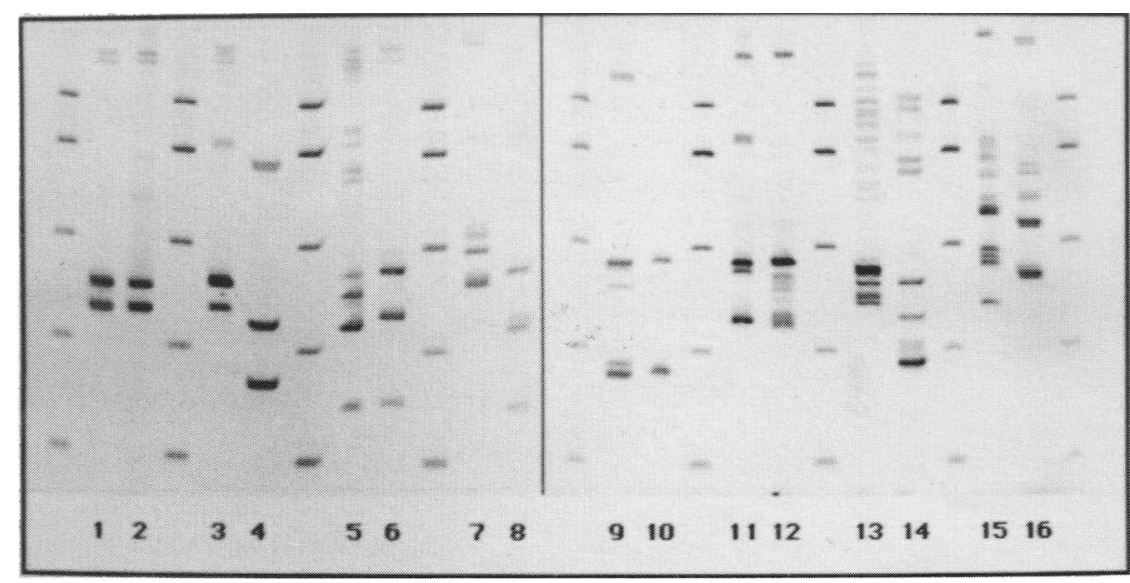

FIGURE 6 Composite photograph showing PCR amplification products for the same bacterial genomic DNA samples described in Fig. 2 with a modified amplification protocol. The sample location and lane designation are the same as Figure 2. The modified amplification conditions consisted of $0.2 \mathrm{mM}$ dNTPs, $1.0 \mu \mathrm{M}$ primers (G17 and L17), and a reaction buffer of $50 \mathrm{mM} \mathrm{KCl}$, $10 \mathrm{mM}$ Tris- $\mathrm{HCl}$ ( $\mathrm{pH} \mathrm{8.3),} 1.5 \mathrm{mM} \mathrm{MgCl}_{2}$, and $0.0003 \%$ gelatin. A total of 20 cycles were run under the following conditions: $15 \mathrm{sec}$ at $94^{\circ} \mathrm{C}, 4 \mathrm{~min}$ at $55^{\circ} \mathrm{C}$, and $1 \mathrm{~min}$ at $72^{\circ} \mathrm{C}$. The final cycle was followed by an additional $7 \mathrm{~min}$ at $72^{\circ} \mathrm{C}$. Unlabeled lanes contain molecular mass markers. Molecular mass markers, gel composition, electrophoresis, and staining conditions are described in Fig. 2.

cant decrease in the production of such fragments as shown in Figure 6.

To demonstrate further that the slower moving bands are not generated directly by polymerase synthesis, the products shown in Figure 6 were subjected to an additional temperature cycle after the polymerase had been inactivated by the addition of EDTA. This temperature cycle consisted of $15 \mathrm{sec}$ at $94^{\circ} \mathrm{C}, 4 \mathrm{~min}$ at $61^{\circ} \mathrm{C}$, and $1 \mathrm{~min}$ at $72^{\circ} \mathrm{C}$. Figure 7 shows clearly that a number of new products were formed for each of the sample species. The majority of these products correspond directly with fragments observed in Figure 2 and with the denatured amplification products in Figure 3 . Because the polymerase is inactive, these products must result from cross-hybridization events and the failure of some single-stranded components to rehybridize.

\section{Single-stranded Endonuclease Digestion of Amplification Products}

Because the lower mobility amplification products contain single-stranded DNA, these structures should be sensitive to a single-stranded endonuclease such as mung bean nuclease. Figure 8 shows that when amplification products from Figure 2 were treated with mung bean nuclease, all of the products with apparent sizes $>880$ bases were removed. A number of shorter bands, including the $E$. coli product at $520 \mathrm{bp}$, also could no longer be seen. In their place, a number of new, fainter fragments in the size range of $150-400 \mathrm{bp}$ could be seen for 8 of the 16 species in the test panel. These smaller fragments are probably residual double-stranded components re- maining after the digestion of singlestranded portions of heteroduplex DNA structures. The absence of these fragments for some species probably indicates that their cross-hybridization products possessed a sufficient number of sequence mismatches to allow the endonuclease to digest them into fragments too small to be observed. The undigested bands in Figure 8, which are common to Figure 2, are believed to be the true homoduplex 16S/23S spacer amplification products. The sizes of these fragments are summarized in Table 1.

\section{Electrophoretic Mobility of Single-stranded and Heteroduplex DNA Structures}

The mobility of PCR products possessing some single-stranded character is profoundly influenced by electrophoretic conditions. Figure 9 shows the effect of voltage and running buffer ionic strength on the electrophoretic separation of $E$. coli and $S$. sonnei amplification products. Regardless of electrophoresis conditions, each of the homogeneous spacer amplification products of 480 and 540 bp shows the same mobility relative to the molecular mass markers. However, when the electrophoresis voltage is decreased or the ionic strength is increased, the apparent mobility of the other amplification products is increased

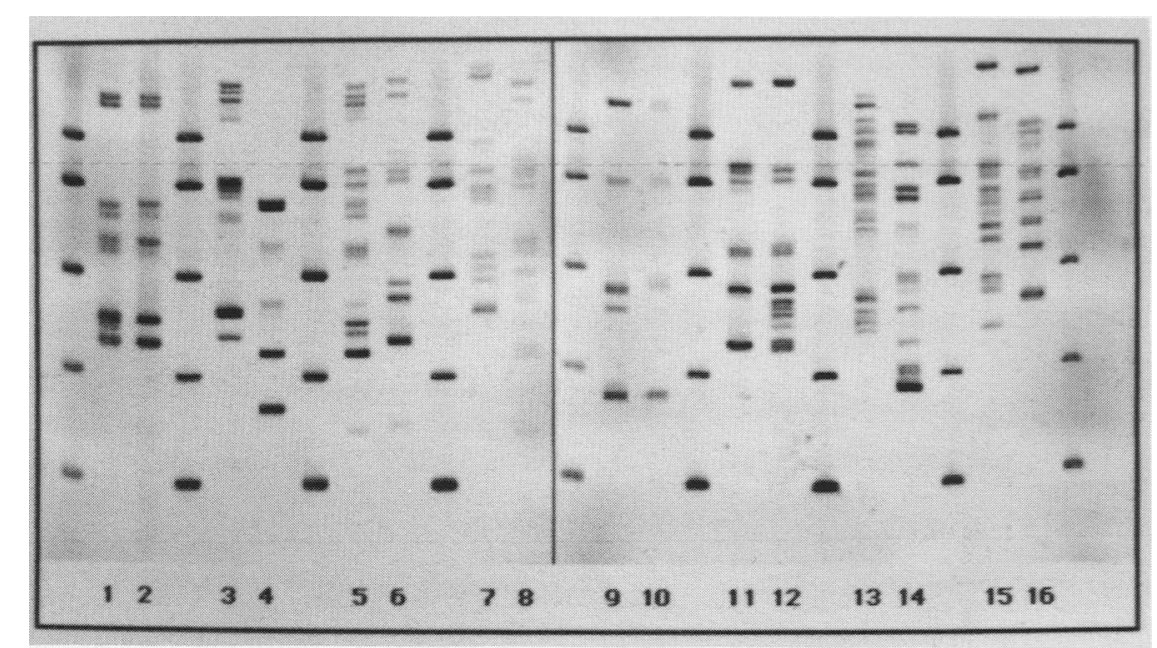

FIGURE 7 Composite photograph showing the results of denaturing and reannealing the amplification products shown in Fig. 6. Products generated using the modified amplification protocol were mixed 1:1 with $10 \mathrm{~mm}$ EDTA and subjected to the following single temperature cycle: $15 \mathrm{sec}$ at $94^{\circ} \mathrm{C}, 4 \mathrm{~min}$ at $61^{\circ} \mathrm{C}$, and $1 \mathrm{~min}$ at $72^{\circ} \mathrm{C}$. The sample location and lane designation are the same as Fig. 2 . The profile in each lane should be compared with the corresponding profiles of Figs. 2 and 3. Unlabeled lanes contain molecular mass markers. Molecular mass markers, gel composition, electrophoresis, and staining conditions are described in Fig. 2. 


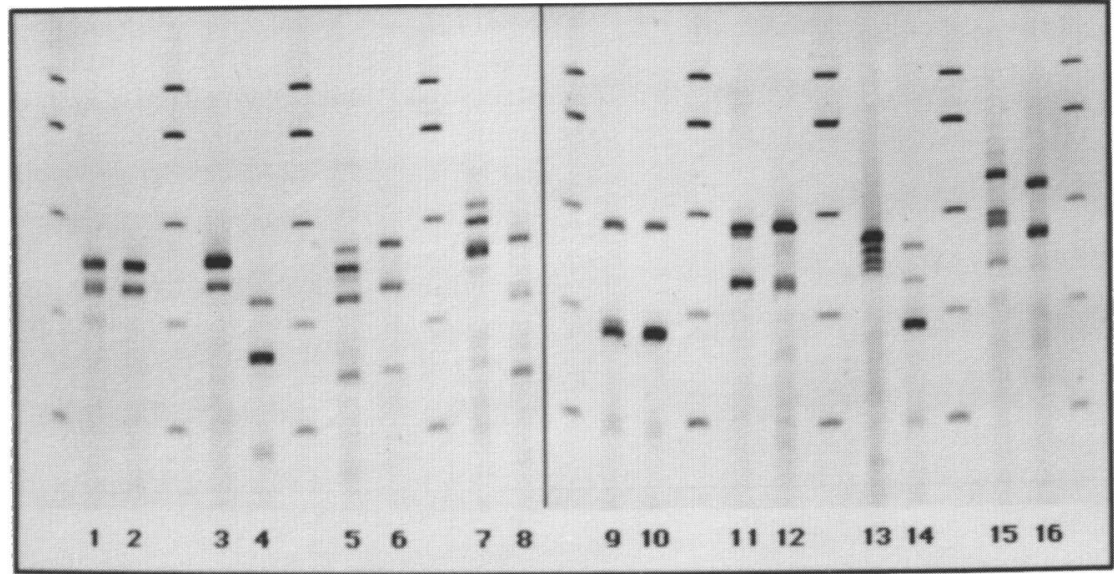

FIGURE 8 Composite photograph showing the results of a mung bean nuclease digest of the amplification products shown in Fig. 2. Sample location and lane designation are the same as Fig. 2. Unlabeled lanes contain molecular mass markers. Molecular mass markers, gel composition, electrophoresis, and staining conditions are described in Fig. 2. markedly. This behavior is not unexpected in DNA that has some singlestranded composition. As the electrophoresis voltage is decreased there is a corresponding decrease in current and gel temperature, which permits the formation of additional secondary structure in the single-stranded portion of the DNA. Increasing the ionic strength of the electrophoresis buffer raises the DNA duplex melting temperature, which also results in increased secondary structure formation. As this double-stranded character increases, the DNA becomes more compact and its relative mobility increases. In comparing the extreme cases of high voltage and low ionic strength versus low voltage and high ionic strength, an average $70 \%$ increase in mobility was observed for the singlestranded products. The slowest moving group of fragments, which are thought to consist of heteroduplex DNA with a significant single-stranded component, also showed a similar mobility dependence.

\section{Discussion}

In the amplification of ribosomal sequences, the formation of single-stranded DNA is influenced by a number of factors. The example of $E$. coli rDNA spacer amplification shown in Figure 4 clearly indicates that asymmetry in the utilization of the G17 and L17 primers contributes to the formation of single-stranded products. On the basis of percent GC composition, $41 \%$ for $\mathrm{G} 17$ and $59 \%$ for
L17, the estimated melting temperature for G17 should be $\sim 7^{\circ}$ lower than for L17. Under stringent amplification conditions this $7^{\circ}$ differential results in a significantly lower priming efficiency for the G17 primer. The effects of this lower priming efficiency can be overcome by an eightfold increase in the concentration of G17. Considering the difference in melting temperature for this pair of primers, it is likely that asymmetric primer utilization is also responsible for the formation of single-stranded DNA amplification products in the remaining 15 strains of bacteria in the test panel.

TABLE 1 Size Summary for Homogeneous Duplex DNA Generated by the Amplification of the 16S/23S rDNA Spacer from G17 and L17 Priming Sites

\begin{tabular}{ll}
\hline $\begin{array}{l}\text { Species and strain } \\
\text { (ID number) }\end{array}$ & $\begin{array}{l}\text { Size of homogeneous duplex } \\
\text { spacer amplification products }(b p)^{a}\end{array}$ \\
\hline
\end{tabular}

Escherichia coli (6)

Shigella sonnei (699)

Serratia marcescens (10)

Enterococcus faecalis (130)

Enterobacter cloacae (123)

Citrobacter freundii (744)

Klebsiella pneumoniae (210)

Listeria monocytogenes (653)

Listeria welshimeri (1174)

Salmonella typhimurium (586)

Salmonella enteritidis (737)

Staphylococcus aureus (684)

Staphylococcus epidermidus (382)

Proteus mirabilis (257)

Proteus morganella (363)
Hafnia alvei (748)
The most direct means of overcoming this asymmetric utilization of primers would be to balance the GC content of the primers. Unfortunately, the amplification of $16 \mathrm{~S} / 23 \mathrm{~S}$ intergenic spacers from highly conserved sequences immediately adjacent to the spacer region does not present this option. A more favorable GC match cannot be achieved without sacrificing either the conserved character of the priming sites or their proximity to the intergenic spacer. In situations where it is not feasible to balance the GC composition of the primers, other modifications can be made to the amplification conditions to enhance the kinetics and relative stability of primer/ template annealing. Utilization of lower annealing temperature, higher ionic strength, and higher primer concentration can decrease the influence of the melting temperature differential. Use of these types of modifications in the amplification of $16 \mathrm{~S} / 23 \mathrm{~S}$ intergenic spacers results in a significant decrease in the relative amount of single-stranded DNA. A similar effect is also achieved by reducing the number of amplification cycles.

PCR amplification of rDNA and rDNA spacer regions from bacterial genomic DNA represents a specialized case, where multiple products are generated containing significant regions of homologous sequences. In early stages of the amplification process, when the primer to template ratio is extremely high, the formation of the primer/template duplex is
${ }^{\text {a Fragment sizes include } \sim 80 \text { bases of } 16 \mathrm{~S} \text { and } 23 \mathrm{~S} \text { sequence. Actual spacer sizes will be } 80 \text { bases }}$ shorter than the lengths reported here. 


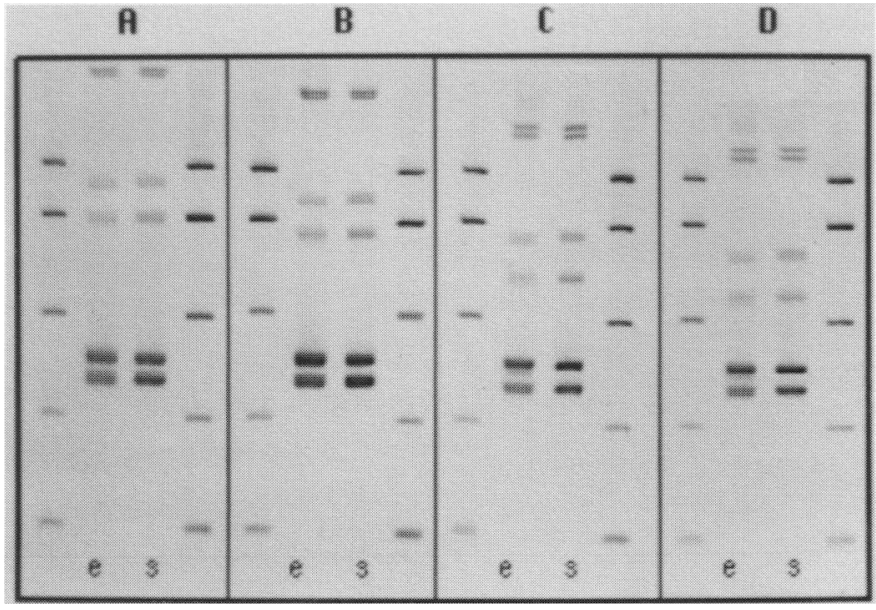

FIGURE 9 Composite photograph showing the results of running the $E$. coli (e) and S. sonnei (s) amplification products shown in Fig. 2 under the following electrophoresis conditions: $(A) 0.5 \times$ TBE, $22.4 \mathrm{~V} / \mathrm{cm}$ for $25 \mathrm{~min}$; $(B) 0.5 \times \mathrm{TBE}, 14 \mathrm{~V} / \mathrm{cm}$ for $45 \mathrm{~min}$; $(C) 1.0 \times \mathrm{TBE}, 14 \mathrm{~V} / \mathrm{cm}$ for $55 \mathrm{~min}$; (D) $1.0 \times \mathrm{TBE}, 8.4 \mathrm{~V} / \mathrm{cm}$ for $150 \mathrm{~min}$. Unlabeled lanes contain molecular mass markers. Molecular mass markers, staining conditions, and gel composition are described in Fig. 2.

kinetically favored over the rehybridization of previously synthesized products. In later cycles, amplification product concentrations reach a sufficiently high level for rehybridization of these products to effectively compete with the formation of the primer/template duplex. When the rehybridizing strands contain sections of noncomplementary sequence, a new heteroduplex product is observed. Because rehybridized products formed in the last amplification cycle do not encounter any additional denaturing steps, these structures will be present in the final amplification mixture.

The persistent formation of heteroduplex DNA during rDNA spacer amplification indicates that the multiple $r r n$ loci of each bacterial genome possess substantial lengths of homologous sequences at both the $16 \mathrm{~S}$ and $23 \mathrm{~S}$ regions flanking the variable spacer regions. Because heteroduplex DNA structures were observed in the amplification products of all 16 bacterial species, this feature is clearly common to all of the species represented in the test group. It was not possible to completely eliminate the formation of heteroduplex DNA within the range of conditions used to amplify prokaryotic rDNA spacer regions. To unambiguously identify homologous double-stranded rDNA spacer amplification products, which were free of heteroduplex and single-stranded DNA, it was necessary to treat the amplification product with a single-stranded endonuclease.
Although the size and number of fragments produced by amplification of the $16 S / 23 S$ ribosomal spacer region can be a useful tool in identifying species of bacteria, there are cases where differences in products can be difficult to resolve in the types of short gels that lend themselves to rapid electrophoretic screening. E. coli and $S$. sonnei each generate similar double-stranded spacer amplification products of 480 and $540 \mathrm{bp}$. In situations of this type, the presence of single-stranded and heteroduplex DNA structures can provide additional information that is helpful in distinguishing each species. In a technique described as single-strand conformation polymorphism (SSCP), it has been shown that small variations in sequence composition of singlestranded DNA can result in measurable differences in electrophoretic mobility. ${ }^{(16)}$ Although the double-stranded products for $E$. coli and $S$. sonnei are of a similar size, slight differences in the electrophoretic mobilities of the singlestranded products, most apparent at low voltage and high ionic strength (Fig. 9D), make it possible to differentiate the strains of these two species. Under certain electrophoresis conditions a heteroduplex product can also be seen just below the 540-bp amplification product of E. coli. No such band is observed in the same region for $S$. sonnei.

Whenever DNA amplification from repetitive sequences is used to generate multiple genetic markers, such as in
RAPD or AP-PCR procedures, the resulting products will have homologous $3^{\prime}$ and 5 ' ends. Although the length of homologous sequence in such products will generally be shorter than the homologous sequences of rDNA spacer amplification products described in this paper, the formation of some heteroduplex DNA structures should not be ruled out. The probability of forming such structures grows significantly as the number of amplification cycles is increased. The formation of heteroduplex DNA can be extremely useful in providing additional pattern information, which helps in the differentiation of similar organisms. However, the presence of such fragments also creates two additional complications. First, if the heteroduplex structures contain significant regions of single-stranded DNA, the relative mobility of such structures will be extremely sensitive to electrophoresis conditions. Such fragments are difficult to use in a DNA identification procedure, which relies on the generation of highly reproducible patterns for comparison with a reference pattern data base. Second, attempts to map individual elements of multicomponent patterns must be cognizant that any heteroduplex DNA structures in the pattern are composed of single-stranded sequences from two distinct genetic loci. This is clearly an important consideration in the mapping of such fragments. Because of these complications, there may be occasions when it is desirable to ensure that heteroduplex structures are not present in the PCR products. If the formation of heteroduplex DNA is suspected, these structures can be removed by digestion with a single-stranded endonuclease prior to electrophoretic separation.

\section{ACKNOWLEDGMENTS}

We thank Dr. John Webster for his invaluable assistance in bacterial identification. We also thank Eileen Cole and James Bruce for their assistance with DNA isolation and Drs. Charles Robertson and Romeo Hubner for their assistance in data acquisition and analysis.

\section{REFERENCES}

1. Jensen, M.A., J.A. Webster, and N. Straus. 1993. Rapid identification of bacteria based on polymerase chain-reaction amplified ribosomal DNA spacer polymor- 
phisms. Appl. Environ. Microbiol. 59: 945952 (patent pending).

2. Williams, J.G.K., A.R. Kubelik, K.J. Livak, J.A. Rafalski, and S.V. Tingey. 1990. DNA polymorphisms amplified by arbitrary primers are useful as genetic markers. $\mathrm{Nu}$ cleic Acids Res. 18: 6531-6535.

3. Welsh, J. and M. McClelland. 1990. Fingerprinting genomes using PCR with arbitrary primers. Nucleic Acids Res. 18: 7213-7218.

4. Welsh, J., C. Petersen, and M. McClelland. 1990. Polymorphisms generated by arbitrarily primed PCR in the mouse: Application to strain identification and genetic mapping. Nucleic Acids Res. 19: 303-306.

5. Goodwin, P.H. and S.L. Annis. 1991. Rapid identification of genetic variation and pathotype of Leptosphaeria maculans by Random Amplified Polymorphic DNA assay. Appl. Environ. Microbiol. 57: 24822486.

6. Brosius, J., T.J. Dull, D.D. Sleeter, and H.F. Noller. 1981. Gene organization and primary structure of a ribosomal RNA operon from Escherichia coli. J. Mol. Biol. 148: 107-127.

7. Grimont, F. and P.A.D. Grimont. 1986. Ribosomal ribonucleic acid gene restriction patterns as potential taxonomic tools. Annu. Inst. Pasteur/Microbiol. 137B: 165175.

8. Webster, J.A. January 1988. U.S. patent $4,717,653$.

9. Dams, E., L. Hendriks, Y. Van de Peer, J. Neefs, G. Smits, I. Vandenbempt, and R. De Wachter. 1988. Compilation of small ribosomal subunit RNA sequences. $\mathrm{Nu}$ cleic Acids Res. (Suppl.) 16: r87-r171.

10. Gutell, R.R. and G.E. Fox. 1988. A compilation of large subunit RNA sequences presented in a structural format. Nucleic Acids Res. (Suppl.) 16: r175-r201.

11. Morgan, E.A., T. Ikemura, L.E. Post, and M. Nomura. 1979. tRNA genes in ribosomal RNA operons of Escherichia coli. In Transfer RNA: Biological aspects (ed. D. Soll, J. Abelson, and P. Schimmel), pp. 259-266. Cold Spring Harbor Laboratory, Cold Spring Harbor, New York.

12. Young, R.A., R. Macklis, and J.A. Steitz. 1979. Sequence of the 16S-23S spacer region in two ribosomal RNA operons of Escherichia coli. J. Biol. Chem. 254: 3264 3271.

13. Becker-André, M. and K. Hahlbrock. 1989. Absolute mRNA quantification using the polymerase chain reaction (PCR). A novel approach by a PCR aided transcript titration assay. Nucleic Acids Res. 17: 94379446.

14. Hsieh, C.-H. and J.D. Griffith. 1989. Deletions of bases in one strand of duplex DNA, in contrast to single-base mismatches, produce highly kinked molecules: Possible relevance to the folding of single-stranded nucleic acids. Proc. Natl.
Acad. Sci. 86: 4833-4837.

15. Ruano, G. and K.K. Kidd. 1992. Modeling of heteroduplex formation during PCR from mixtures of DNA templates. $P C R$ Methods Applic. 2: 112-116.

16. Orita, M., H. Iwahana, H. Kanazawa, K. Hayashi, and T. Sekiya. 1989. Detection of polymorphisms of human DNA by gel electrophoresis as single-strand conformation polymorphisms. Proc. Natl. Acad. Sci. 86: 2766-2770.

Received May 10, 1993; accepted in revised form October 1, 1993. 


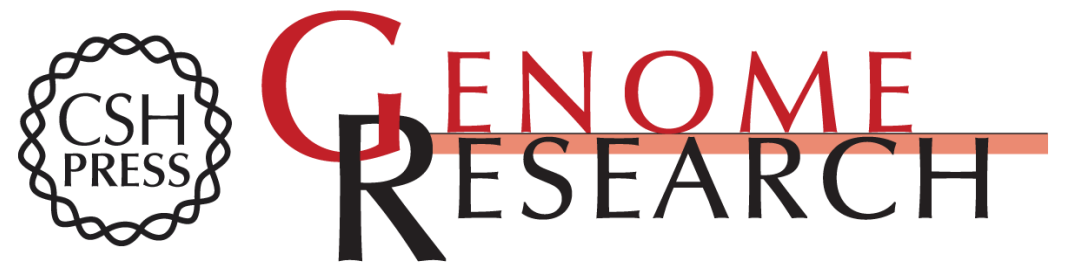

\section{Effect of PCR conditions on the formation of heteroduplex and single-stranded DNA products in the amplification of bacterial ribosomal DNA spacer regions.}

$\mathrm{M} A$ Jensen and N Straus

Genome Res. 1993 3: 186-194

References This article cites 14 articles, 5 of which can be accessed free at:

http://genome.cshlp.org/content/3/3/186.full.html\#ref-list-1

\section{License}

Email Alerting

Receive free email alerts when new articles cite this article - sign up in the box at the Service top right corner of the article or click here.

\section{Affordable, Accurate Sequencing.}

